\title{
Self-medication practices and misuse of medicine among mothers of young children attending a teaching hospital in Sri Lanka
}

\author{
*Bhagya Piumali de Silva ${ }^{1}$, Fathima Hasna Hussain ${ }^{1}$, Gayathri Ginige ${ }^{1}$, Amani Kulathunge ${ }^{1}$, Hasni \\ Kannangara $^{1}$, Sampatha Goonawardane ${ }^{1}$, Manori Gamage ${ }^{1}$
}

Sri Lanka Journal of Child Health, 2017; 46(2): 122-127

\begin{abstract}
Background: Self-medication and misuse of medicines is a growing trend in current society.

Objectives: To assess the self-medication practices, misuse of selected oral allopathic medication and associated factors among mothers of children under 12 years attending the outpatient department (OPD) of Colombo South Teaching Hospital (CSTH).
\end{abstract}

Method: A descriptive cross sectional study was carried out among mothers of children under 12 years of age who attended the OPD of CSTH from March to April 2014 on self-medication of selected oral medicines in the preceding six months. Data was collected by a pre-tested intervieweradministered questionnaire and was analysed using SPSS 15.0.

Results: Eighty five percent of the 350 study participants were between 25-44 years with a mean age of $33.1 \pm 6.7$ years. Eighty seven percent of them were Sinhalese, $74 \%$ were only educated up to the ordinary level $(\mathrm{O} / \mathrm{L})$ and $64 \%$ were housewives. There were $54 \%$ female children and $51 \%$ were between $1-4$ years of age. Ninety five percent participants self-medicated their children. There was a statistically significant association between mother's higher education level $(p<0.05)$, unemployed mothers $(p<0.01)$, father's higher education level $(p<0.01)$, father's higher occupational category $(\mathrm{p}<0.05)$, increased age of child $(\mathrm{p}<0.01)$ and high parity $(\mathrm{p}<0.05)$ with selfmedication. Paracetamol was the drug used for self-medication by $92 \%$ whilst $8 \%$ used salbutamol, amoxicillin and chlorpheniramine.

\section{${ }^{1}$ Faculty of Medical Sciences, University of Sri Jayewardenepura, Sri Lanka \\ *Correspondence: bhagyadesilva26@gmail.com}

(Received on 17 June 2016: Accepted after revision on 26 August 2016)

The authors declare that there are no conflicts of interest

Personal funding was used for the project.

Open Access Article published under the Creative

Commons Attribution CC-BY (CC)
Significant association with misuse of paracetamol was observed among housewives $(p<0.01)$, low educational level of participants and spouse ( $p$ $<0.05)$, skilled occupations $(\mathrm{p}<0.05)$, older age of child $(\mathrm{p}<0.001)$ and having nuclear families $(\mathrm{p}<0.05)$. Chlorpheniramine overuse was significantly associated with female child and nuclear family type $(\mathrm{p}<0.05)$.

Conclusions: Ninety five percent of mothers attending the OPD in CSTH during the study period self-medicated their children. There were statistically significant associations between higher educational level of mothers, unemployed mothers, increasing age of child and increasing number of children with the tendency to self-medicate the child.

DOI: http://dx.doi.org/10.4038/sljch.v46i2.8267

(Key words: Self-medication, misuse of oral allopathic medication, children under 12 years)

\section{Introduction}

Despite the widespread use of self-medication among children and its potential harm, up-to-date epidemiological data on self-medication are sparse worldwide $^{1}$. The term self-medication can be defined as patients consuming nonprescription medicines, usually over-the-counter (OTC) drugs, to treat certain 'minor' ailments themselves without consulting a medical practitioner and without any medical supervision ${ }^{1}$. The World Health Organization (WHO) defines self-medication as "use of pharmaceutical or medicinal products by the consumer to treat self-recognized disorders or symptoms, the intermittent or continued use of a medication previously prescribed by a physician for chronic or recurring disease or symptom, or the use of medication recommended by lay sources or health workers not entitled to prescribe medicine"2. Self-medication may also cause masking of symptoms and may probably cause side effects ${ }^{1}$. An example is Reye's syndrome in children due to aspirin. Many cases of acetaminophen (paracetamol) misuse are widely reported. A study done in National Hospital of Sri Lanka in 2006 states the admissions with acute paracetamol poisoning to the National Hospital of Sri Lanka (NHSL) have increased from 35 in 2003 to 515 in $2005^{3}$. With the increase in knowledge of 
pharmaceuticals, some mothers are familiar with the brand names of certain medicines. Therefore they have a high chance of trying to diagnose the child's condition and trying different sources of drugs before consulting a medical practitioner. However, there have been many cases where such drugs may have masked the symptoms; aggravated them or caused adverse side effects. Thus, it is of paramount importance to find out what the practices are among mothers on self-medication; the reasons for self-medication; attitudes towards them and the current situation of usage in an urban area.

\section{Objectives}

To assess the prevalence of self-medication practices and misuse of selected oral allopathic medicine and associated factors among mothers of children less than 12 years of age attending the outpatient department (OPD) of Colombo South Teaching Hospital (CSTH).

\section{Method}

A hospital based descriptive, cross sectional study was conducted in the OPD of CSTH (which has an average daily attendance of about 500 patients) from March to April 2014. Mothers of children under the age of 12 who can converse in Sinhala / English, attending OPD at CSTH, comprised the study population. The following were excluded: mothers of children under the age of 1 year, mothers of children with debilitating illnesses, mothers of children with deformities and mothers who can only converse in Tamil. Sample size calculated from the standard equation was 345 . Sampling technique was simple random sampling without replacement. Those who fulfilled the eligibility criteria were selected and data was collected using a pre-tested intervieweradministered questionnaire. Information on selfmedication of children below 12 years of age in the preceding six months were inquired from mothers after obtaining permission from the Director of CSTH and the Medical Officer In Charge of OPD and after obtaining informed verbal consent from the mothers. Self-medication was defined as the use of medicines that had either been bought OTC, or obtained from other sources and used to treat the child after self-diagnosis and prior to medical consultation. Self-medication using oral allopathic medicines was considered. The questionnaire included sociodemographic factors, commonly used self-medication, reasons for self-medication and misuse of selected medicines. To determine the relationship between the primary study factors and various behaviours, descriptive statistics and analytical tools such as frequency tables, cross tabulation and appropriate statistical tests were used. Data were analysed using SPSS package version 15.0. Ethical clearance was obtained by the Ethics Review Committee of the Faculty of Medical Sciences, University of Sri Jayewardenepura and from the Ethical Review Committee of CSTH.

\section{Results}

The sociodemographic factors of the study population are shown in Table 1.

Table 1: Sociodemographic factors of study population $(n=350)$

\begin{tabular}{|l|c|}
\hline \multicolumn{1}{|c|}{ Characteristic } & Number (\%) \\
\hline Age of mother (years) & $31(08.9)$ \\
$15-24$ & $187(53.4)$ \\
$25-34$ & $111(31.7)$ \\
$35-44$ & $21(06.0)$ \\
$45-54$ & \\
\hline Mother's educational level & $258(73.7)$ \\
Ordinary Level (O/L) or & $92(26.3)$ \\
less & \\
Higher than O/L & $189(54.0)$ \\
\hline Sex of child & $161(46.0)$ \\
Female & $177(50.6)$ \\
Male & $124(35.4)$ \\
Age of child (years) & $49(14.0)$ \\
1-4 & \\
5-8 & $198(56.6)$ \\
9-12 & $152(43.4)$ \\
\hline Family type & $327(93.4)$ \\
Nuclear & $23(06.6)$ \\
\hline Extended & \\
\hline Number of children & \\
3 or less & \\
More than 3 & \\
\hline
\end{tabular}

Two hundred and ninety eight $(85 \%)$ of the 350 participants were between 25-44 years and the mean age of the mothers was $33.1 \pm 6.707$ years. Eighty seven percent were Sinhalese, $74 \%$ were only educated up to Ordinary Level (O/L) and 64\% were housewives. Fifty four percent were girls and $51 \%$ were between 1-4 years of age. Fifty seven percent of study participants were from nuclear families and $93 \%$ of families had less than 3 children. (Table 1).

Three hundred and thirty one (95\%) mothers selfmedicated their children. Mild symptoms was the reason for self-medication by $89 \%$ mothers. Acetaminophen (paracetamol) was the drug used by $92 \%$ whilst $8 \%$ used salbutamol, amoxicillin and chlorpheniramine. Among the common conditions that the mothers self-medicated children were headache $(18 \%)$ common cold $(16 \%)$ and fever $(15 \%)$. In our study population, antacids, antidiarrhoeals, bronchodilators, antibiotics, vitamins, antiemetics, antihistamines and analgesics were used as self-medication only in older children (over 
the age of 5 years). Eighty percent had obtained medicines without prescriptions, but this also includes OTC medicines. Eighty six percent of mothers who self-medicated their children with antibiotics obtained it from a pharmacy without prescription. The important sources of information regarding self-medication were immediate family (44\%) pharmacists $(24.5 \%)$ and the media $(21.5 \%)$. The association between self-medication (with drugs other than paracetamol) and sociodemographic factors is shown in Table 2.

Table 2: Association between self-medication (excluding paracetamol) and sociodemographic factors of mother

\begin{tabular}{|l|c|c|c|}
\hline \multicolumn{1}{|c|}{ Characteristic } & $\begin{array}{c}\text { Self-medicated } \\
\text { Number (\%) }\end{array}$ & $\begin{array}{c}\text { Did not self-medicate } \\
\text { Number (\%) }\end{array}$ & Significance* \\
\hline Age of mother (years) & $09(32.1)$ & $19(67.9)$ & \\
$15-24$ & $64(36.6)$ & $111(63.4)$ & $\mathrm{p}=0.069 ; \mathrm{p}>0.05$ \\
$25-34$ & $45(42.6)$ & $07(57.4)$ & \\
$35-44$ & $13(65.0)$ & $157(63.6)$ & $\mathrm{p}=0.011 ; \mathrm{p}<0.05$ \\
$45-54$ & $90(36.4)$ & $42(50.0)$ & \\
\hline Mother's educational level & $42(50.0)$ & $86(69.9)$ & $\mathrm{p}=0.005 ; \mathrm{p}<0.01$ \\
Ordinary Level (O/L) or less & $37(34.2)$ & $113(54.3)$ & \\
Higher than O/L & $95(56.7)$ & & \\
\hline Mother's occupational & & $114(69.1)$ & \\
status & $51(30.9)$ & $59(50.4)$ & $\mathrm{p}=0.004 ; \mathrm{p}<0.01$ \\
Employed & $58(49.6)$ & $26(53.1)$ & $\mathrm{p}=0.033 ; \mathrm{p}<0.05$ \\
Unemployed (Housewife) & $23(46.9)$ & $190(61.7)$ & \\
\hline Age of child (years) & $118(38.3)$ & $09(39.1)$ & \\
1-4 & $14(60.9)$ & & \\
5-8 & & & \\
9-12 & & & \\
\hline Number of children & & & \\
3 or less & & & \\
More than 3 & & & \\
\hline
\end{tabular}

*Chi Squared test

According to table 2, the highest percentage of selfmedication was by mothers who had obtained higher education, and mothers who were unemployed $(p<0.01)$. The tendency of selfmedication increased with the age of the child $(p<0.01)$. A significant association was observed between the number of children in the family and the tendency of self-medication $(p<0.05)$, with more self-medication when the number of children in the family increased.

We inquired into the reasons for self-medication and interestingly, only a minority of the mothers stated long waiting time in queues $(29.0 \%)$, inconvenience caused by health workers $(7.3 \%)$, high cost of drugs prescribed $(19.9 \%)$, high cost of reports to be obtained $(19.6 \%)$, high cost of doctor consultation $(25.4 \%)$, consultations being time consuming (29.6\%), having many children (12.7\%), long distance to a medical practitioner $(25.7 \%)$, busy schedule in workplace $(10.3 \%)$ and lack of transport $(21.5 \%)$. Eighty nine percent implied "symptoms being mild" as the main reason for self-medication but it was not statistically significant. $(p=0.932, p>0.05)$. From all the reasons mentioned above only "busy schedule in the work place" showed a statistical significance with selfmedication $(p=0.002, p<0.01)$.

We also assessed the practices of dosing in two selected drugs, paracetamol and chlorpheniramine, when mothers use them as self-medication. We obtained the dose given for the specific child and compared it with the paracetamol dose for weight and the recommended dose for chlorpheniramine. We then categorized mothers who gave more than $2 \mathrm{ml}$ of syrup above the appropriate dose and more than half a tablet above the appropriate paracetamol dose for weight and chlorpheniramine as "larger dose than that appropriate for weight". Out of the mothers who had used paracetamol, 23.4\% had used a larger than recommended dose whilst $12 \%$ had used a larger than recommended dose of chlorpheniramine. Significant association with misuse of paracetamol was observed among housewives $(\mathrm{p}=0.001, \mathrm{p}<0.01)$, low educational level of participants and spouse $(\mathrm{p}<0.05)$, skilled occupations $(\mathrm{p}=0.02, \mathrm{p}<0.05)$, older age of child $(\mathrm{p}=0.000, \mathrm{p}<0.001)$ and having nuclear families $(p<0.05)$. Chlorpheniramine overuse was significantly associated with female child and nuclear family type $(\mathrm{p}<0.05)$. 
Self-medication practices and misuse of medicine ... Sri Lanka Journal of Child Health, 2017; 46(2):122-127

Discussion

Ninety five percent of mothers who attended the OPD in CSTH self-medicated their children and they were mostly from urban areas and having a low educational level. A similar study done in Sri Lanka in 2005 revealed $85 \%$ of mothers selfmedicated their children ${ }^{6}$. According to a study done in Germany (KiGGS) $25.2 \%$ of participants have used self-medication ${ }^{1}$. In a study by Kogan et al in 1994, $54.7 \%$ of all 3 year children in United States were given some OTC medication ${ }^{7}$. Most $(73 \%)$ mothers reported having used OTC medication for their children in Western Australia ${ }^{8}$. A study done in Nepal has shown a prevalence of $85 \%$ of self-medication among children ${ }^{4}$.

In our study, there was no association between mother's age and self-medication. However, there was a statistically significant association between the mother's educational level and the tendency to self-medicate the child. The study by Kariyawasam et al shows there is an increased proportion in selfmedication to children among mothers who have middle to high education level ${ }^{6}$. A survey done in Germany "(KiGGS)"1 also quotes "Our previous study indicated that the use of such medicines was closely associated with a higher socioeconomic status and higher educational levels among mothers". According to our research, most of the mothers who self-medicate were unemployed and similar findings were reported in Sri Lanka in $2005^{6}$.

Symptoms being mild was a major reason for selfmedication among this population of mothers. Shankar PR et al concluded that the common reasons for self-medication were mild illness, previous experience of treating a similar illness, and non-availability of health personnel ${ }^{4}$. A study in North West Ethiopia showed that poverty and low severity of symptoms were the two major reasons for self-medication ${ }^{5}$. In our study a highest percentage of mothers who self-medicated mentioned busy schedule in workplace as one of the reasons. This may be since most of them were from an urban area. A study by Kayode et $\mathrm{al}^{9}$ demonstrated common reasons for practising selfmedication as long delays in the health centres, previous experience of medical treatment of the same symptoms, illness being considered too trivial and health centres not being socially accessible. The study also stated that some people may engage in the practice due to ignorance, poverty and nonavailability of health facilities. The above two research findings are in contrast to our findings and this may be due to Sri Lanka having a good primary health care system and better quality health service.
In our study, paracetamol was the drug used for self-medication by the majority followed by salbutamol, amoxicillin and chlorpheniramine. Similar results were obtained in a 2015 study by Pushpa et $\mathrm{al}^{10}$ and paracetamol, oral rehydration salts (Jeevani), menthol rub, antibiotics, chlorpheniramine, anthelmintics, mebendazole and gripe water, methyl salicylate compound, salbutamol, antifungal candid creams, beclomethasone and ear drops were the drugs identified in decreasing order. Menthol rubs, Jeevani and Ayurvedic medicines were beyond the scope of our research.

The commonest conditions identified for which self-medication was done were fever, common cold, stomachache, wheeze and headache. It was interesting to note that for earache and wheezing episodes, mothers were reluctant to self-medicate either due to perceived lack of knowledge on medicine or perceived increased severity of those conditions. Vitamins, anti-histamines and antibiotics were commonly used by mothers to selfmedicate children more than four years of age. A higher percentage of mothers who self-medicated their children with antibiotics obtained it from a pharmacy without prescription. A study conducted in Yemen reported that $26 \%$ of patients used the previous prescription paper to obtain antibiotics, while $74 \%$ patients obtained antibiotics from pharmacies and drug stores without any need for a prescription $^{11}$. Similar results were observed in our study. However, a drawback in our study was that the above antibiotics could have been the remainder from previous prescriptions, though this cannot account for the entire set. Yu et al reported that $32 \%$ of parents admitted using leftover antibiotics that had been previously prescribed by physicians for similar symptoms ${ }^{12}$. The most significant sources of information for selfmedication were immediate family members, pharmacists and media. A study done in Nepal by Shankar et $\mathrm{al}^{4}$ showed that doctors and previous prescriptions were the two commonest sources identified.

Paracetamol is a commonly used and widely available drug for the paediatric age group. A study by Kozer et $\mathrm{al}^{13}$ concluded that liver injury secondary to repeated dosing of paracetamol is rare but may result in severe morbidity and mortality. The cumulative dose of paracetamol should not exceed $75 \mathrm{mg} / \mathrm{kg} /$ day and it was recommended that children treated with higher doses for more than two days should be evaluated for possible liver injury and treated. Thus we considered a dose more than $2 \mathrm{ml}$ of syrup above the appropriate dose and more than half a tablet above the appropriate paracetamol dose for weight and chlorpheniramine 
as "larger dose than that appropriate for weight"13. In our study, paracetamol was used in quantities more than appropriate dose by $23.4 \%$ and was administered every six hourly by the majority. A study was done in 2001 to assess fulminant hepatic failure due to paracetamol overuse. The findings provided evidence to support that exposure to supra-therapeutic doses of paracetamol contributes to the development of fulminant hepatic failure in febrile children ${ }^{14}$. In our study, significant associations were observed between paracetamol overuse and father's occupation (skilled labourers), lower education level of father, and increased age of child. Housewives were more likely to selfmedicate with overdoses than employed mothers. Older children were self-medicated with more than recommended doses. Chlorpheniramine was used above the recommended amount for the child's age by $12 \%$ of mothers. There were a few limitations in our study viz. the mothers being reluctant to reveal the truth on how they obtain drugs without prescriptions, possibility of recall bias and some mothers self-medicating a child other than the index child.

We recommend educating the mother regarding the correct dosage according to age and weight of child and not to use previous prescriptions for antibiotics. Responsible medical authority should standardize and introduce the chlorpheniramine dose for weight in accessible forms such as the labels of medication and mothers should strictly adhere to the OTC drugs.

\section{Conclusions}

- $\quad$ Ninety five percent of mothers attending the OPD in CSTH during the study period self-medicated their children.

- There were statistically significant associations between higher educational level of mothers, unemployed mothers, increasing age of child and increasing number of children with the tendency to self-medicate the child.

\section{References}

1. Du Y, Knopf H. Self-medication among children and adolescents in Germany: results of the National Health Survey for Children and Adolescents (KiGGS). British Journal of Clinical Pharmacology.2009; 68(4): 599-608. https://doi.org/10.1111/j.13652125.2009.0 3477.x

PMid: 19843063 PMCid: PMC2780285
2. World Health Organization. Guidelines for the Regulatory Assessment of Medicinal Products for Use in SelfMedication. Geneva 2000.

3. Senarathna SMDKG, Ranganathan SS, Dawson AH, Buckley N, Fernandopulle BMR. Management of acute paracetamol poisoning in a tertiary care hospital. Ceylon Medical Journal 2008; 53(3):8992.

https://doi.org/10.4038/cmj.v53i3.248

PMid: 18982801 PMCid: PMC3145136

4. Shankar PR, Partha P, Shenoy N. Selfmedication and non-doctor prescription practices in Pokhara valley, Western Nepal: a questionnaire-based study. $B M C$ Family Practitioner 2002; 3(1):17. https://doi.org/10.1186/1471-2296-3-17 PMCid: PMC130019

5. Teferra A, Alemayehu W. Self-medication in three towns of North West Ethiopia. Ethiopian Journal of Health Development 2001(1); 15:25-30.

6. Kariyawasam SH, Nanayakkara DN, Mohottiarachchi MACP, Nandasena YLS. Descriptive cross sectional study on mothers self-medicating children. Sri Lanka Journal of Child Health, 2005; 34: 7-12

7. Kogan MD, Pappas G, Stella MY, Kotelchuck M. Over-the-counter medication use among US preschool-age children. Journal of the American Medical Association 1994; 272(13):1025-30. https://doi.org/10.1001/jama.272.13.1025 PMid: 8089884

8. Slack-Smith LM, Read AW, Stanley FJ. The use of medication in children attending childcare in Western Australia. Journal of Paediatrics and Child Health 1998; 34: 183-7.

https://doi.org/10.1046/j.14401754.1998.0 0196.x

PMid: 9588646

9. Kayode K. Attitude and practices towards self medication among residents of Ikeja, Lagos residents. Available from: https://www.academia.edu/4161319/Attitu de_and_Practices_towards_Self_Medicati on_among_residents_of_Ikeja_Lagos_resi dents 
10. Pushpa RW, Ravindra LJ, Rohini DAS. Prevalence and predictors of selfmedication in a selected urban and rural district of Sri Lanka. WHO's South East Asia Journal of Public Health 2015; 1(1):28-41.

11. Mabrook M. Self-medication with antibiotic in children in Sana'a City, Yemen. Oman Medical Journal 2010; 25(1): 41-3.

12. Yu M, Zhao G, Stålsby LC, Zhu Y, Zhao $\mathrm{Q}, \mathrm{Xu}$ B. Knowledge, attitudes, and practices of parents in rural China on the use of antibiotics in children: a crosssectional study, BMC Infectious Disease Journal. 2014; 14:112.

https://doi.org/10.1186/1471-2334-14-112

PMid: 24576064 PMCid: PMC3938908
13. Kozer E, Repeated supra-therapeutic dose of paracetamol in children. Acta paeditr. 2006; 95(10): 1165-71.

14. Ranganathan SS, Fernandopulle BM, de Silva MV, Fernandopulle M. Fulminant hepatic failure in a child following paracetamol overdosing. Ceylon Medical Journal 2001; 46(2): 72-3.

PMid: 11727585 